\title{
Hubungan Waktu Penyediaan Dokumen Rekam Medis Dengan Kepuasan Pasien Pada Bagian Pendaftaran Di Rumah Sakit Umum Permata Bunda Medan
}

\author{
Valentina \\ Program Studi D-III Perekam Medis dan Informasi Kesehatan, Universitas Imelda Medan
}

\begin{tabular}{l} 
Article Info \\
\hline Article history: \\
Received Feb12, 2020 \\
Revised Feb 25, 2020 \\
Accepted Feb28, 2020 \\
\hline
\end{tabular}

\section{Keywords:}

Time

Provision of Medical Record

Documents

Patient Satisfaction

Registration

\begin{abstract}
ABSTRAK
Aspects that need to be considered in the medical record service in the registration section so that it has good quality, one of which is the time of providing medical record documents. The purpose of this study was to determine the relationship between the time of providing medical records and patient satisfaction in the registration section at Permata Bunda General Hospital, Medan. The type of research is descriptive using cross sectional design. The population is all outpatients in Permata Bunda General Hospital Medan, which is calculated from the average number of patient visits in one week, which is 307 . Samples totaling 76 people were obtained by accidental sampling technique. The research instrument used observation sheets and interview guidelines. Data were analyzed univariately and bivariately, to prove the relationship between the two variables using the independent t-test statistical test with $95 \% \mathrm{CI}(\alpha=0.05)$. The result of this research is that there is a correlation between the time of providing medical records and patient satisfaction in the registration section at Permata Bunda General Hospital, Medan $(p=0.0001)$. It is recommended to shorten the time for the provision of medical record documents and increase patient satisfaction by carrying out proper and proper medical record management.
\end{abstract}

This is an open access article under the CC BY-SAlicense.

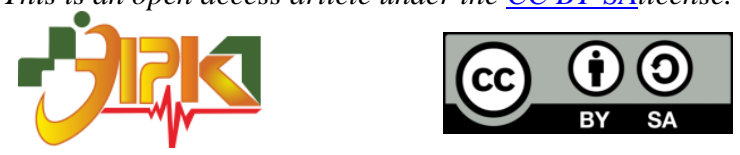

\section{Corresponding Author:}

Valentina,

Program Studi D-III Perekam Medis dan Informasi Kesehatan,

Universitas Imelda Medan,

Jl. Bilal No. 52 Kelurahan Pulo Brayan Darat I Kecamatan Medan Timur, Medan - Sumatera Utara.

Email: valentinave89@gmail.com

\section{PENDAHULUAN}

Sistem pelayanan kesehatan sebuah rumah sakit mencerminkan mutu pelayanan berjalan di dalamnya. Oleh sebeb itu mutu pelayanan kesehatan harus disesuaikan dengan standard profesi melalui pemanfaatan seluruh sumber daya yang ada dengan efektif, demi tercapainya kebutuhan pasien dan derajat kesehatan yang optimal (Bustami, 2011). Mutu pelayanan merujuk pada tingkat kesempurnaan penampilan pelayanan kesehatan yang diselenggarakan pada rumah sakit dengan tata cara penyelenggaraanya sesuai dengan kode etik profesi serta standar yang telah di tetapkan sehingga hasil akhir yang diperoleh dapat memuaskan pasien sebagai pemakai jasa pelayanan kesehatan (Azwar, 1996). Pelayanan 
kesehatan dinilai memiliki mutu yang baik tidak hanya berdasarkan indikator mutu pada pelayanan medis saja melainkan juga pada pelayanan rekam medis (Kemenkes RI, 2008).

Salah satu aspek yang perlu diperhatikan dalam pelayanan rekam medis pada bagian pendaftaran agar memiliki mutu baik adalah lama waktu petugas menyediakan dokumen rekam medis. Pelayanan rekam medis yang diberikan pada bagian pendaftaran yaitu pelayanan pendaftaraan, pencarian dan pendistribusian rekam medis. Lama waktu petugas menyediakan dokumen rekam medis pasien rawat jalan berdasarkan Kemenkes RI tentang Standar Pelayanan Minimal di rumah sakit adalah kurang dari 10 menit untuk pelayanan rawat jalan sedangkan rawat inap tidak lebih dari 15 menit. Waktu penyediaan tersebut dihitung mulai dari ketika pasien selesai melakukan registrasi sampai sampai proses pencarian rekam medis di bagian penyimpanan agar dapat didistribusikan ke poli yang dituju. Lama waktu pasien menunggu merupakan salah satu indikator potensial yang dapat menyebabkan ketidakpuasan pasien. Selain itu pasien akan menilai pelayanan kesehatan yang jelek apabila sakitnya tidak kunjung sembuh, antri terlalu lama, dan petugas kesehatan yang tidak ramah meskipun profesional (Kemenkes RI, 2008).

Kepuasan adalah penilaian dari rasa senang atau kecewa yang timbul setelah membandingkan antara persepsi terhadap kinerja atau jasa dan harapan-harapan. Selain itu kepuasan pasien dapat juga dinilai dari persepsi keluarga terdekat terhadap pelayanan yang sudah diberikan (Asmuji, 2012). Dimensi kepuasan meliputi aspek tangibles (wujud), aspek reliability (keandalan), aspek responsiveness (daya tanggap), aspek assurance (keyakinan/jaminan), aspek empathy (kesediaan untuk peduli) (Zeithhaml P \& Bitner (1996) dalam Hardiansyah, 2011). Penelitian sebelumnya yang berkaitan dengan kepuasan pasien pada pelayanan pendaftaran menyatakan sangat membantu rumah sakit dalam memberikan pelayanan kepada pasien (Erlindai \& Apriana, 2019).

Berdasarkan survey awal ditemukan bahwa terlihat pasien lama menunggu untuk mendapatkan pelayanan rawat jalan. Pasien terlihat bosan, gelisah dan kurangnya komunikasi yang baik antara pasien dengan petugas pendaftaran sehingga terjadinya kesalahpahaman yang menimbulkan rasa kurang nyaman. Terjadi keluhan dari beberapa pasien karena masalah waktu menunggu di pendaftaran agar mendapatkan pelayanan medis secepatnya.

\section{METODE PENELITIAN}

A. Jenis Penelitian

Jenis penelitan yang digunakan adalah deskriptif dengan desain cross sectional. Waktu penelitian dilakukan pada bulan September 2019 sampai Januari 2020. Tempat penelitian ini dilakukan di Rumah Sakit Umum Permata Bunda Medan.

B. Populasi

Populasi penelitian ini adalah seluruh pasien rawat jalan di RSU Permata Bunda Medan. Jumlah populasi pasien dihitung dari rata-rata kunjungan pasien yang datang dalam sehari dalam satu minggu yaitu 307 rekam medis.

C. Sampel

Perhitungan jumlah sampel menggunakan rumus slovin.

$n=\frac{N}{1+N e^{2}}$

$\mathrm{N}$ : jumlah populasi

$\mathrm{n}$ : jumlah sampel

e : batas toleransi kesalahan $(10 \%)$

$=\frac{307}{1+307 \times(0,1)^{2}}$

$=\frac{307}{1+307 \times 0.01}$ 
$=\frac{307}{4,07}$

$=75,4 \approx 76$

Maka jumlah sampel dalam penelitian ini adalah 76 orang pasien rawat jalan. Teknik pengambilan sampel menggunakan accidental sampling. Accidental sampling adalah pengambilan sampel secara aksidental berarti sampel diambil dari responden atau kasus yang kebetulan ada di suatu tempat atau di keadaaan tertentu yang sudah di tetapkan. (Notoadmodjo, 2012).

D. Cara Pegumpulan Data

Cara pengumpulan data yang digunakan adalah observasi, dimana peneliti melakukan pengamatan langsung dengan mencatat data dan menghitung waktu menggunakan stopwatch. Sedangkan wawancara menggunakan kuesioner kepada pasien rawat jalan.

E. Analisis Data

Analisis data dilakukan secara univariat yaitu untuk mendeskripsikan karakteristik setiap variabel penelitian dengan menghasilkan distribusi frekuensi dan persentase dari tiap variabel, dan analisis bivariat yaitu untuk mencari hubungan dua variabel menggunakan uji statistik t-test independen dengan CI 95\%.

\section{HASIL DAN PEMBAHASAN}

\subsection{Hasil}

Hasil penelitian menunjukkan bahwa paling banyak dokumen rekam medis disediakan selama 11 menit yaitu 15 dokumen rekam medis (19,73\%), dan yang paling sedikit disediakan selama 13 menit yaitu 3 dokumen rekam medis (3,99\%). Sedangkan rata-rata penyediaan berkas rekam medis adalah 11,3 menit.

Tabel 1. Waktu Penyediaan Dokumen Rekam Medis

\begin{tabular}{cccc}
\hline No. & Waktu Tunggu & Frekuensi & Persentase \\
\hline 1. & 7 menit & 4 dokumen & $5,26 \%$ \\
\hline 2. & 8 menit & 8 dokumen & $10,52 \%$ \\
\hline 3. & 9 menit & 10 dokumen & $13,15 \%$ \\
\hline 4. & 10 menit & 10 dokumen & $13,15 \%$ \\
\hline 5. & 11 menit & 15 dokumen & $19,73 \%$ \\
\hline 6. & 12 menit & 7 dokumen & $9,21 \%$ \\
\hline 7. & 13 menit & 3 dokumen & $3,99 \%$ \\
\hline 8. & 14 menit & 4 dokumen & $5,26 \%$ \\
\hline 9. & 15 menit & 6 dokumen & $7,89 \%$ \\
\hline 10. & 16 menit & 9 dokumen & $11,84 \%$ \\
\hline \multicolumn{2}{c}{ Rata-rata 11,3 menit } & $\mathbf{7 6}$ dokumen & $\mathbf{1 0 0} \%$
\end{tabular}

Hasil penelitian menunjukan bahwa pasien dalam kategori puas yaitu 45 orang $(59,2 \%)$ dan tidak puas yaitu 31 orang $(40,8 \%)$.

Tabel 2. Distribusi Frekuensi Kepuasan Pasien

\begin{tabular}{cccc}
\hline No. & Kepuasan Pasien & Frekuensi & Persentase \\
\hline 1 & Tidak Puas & 31 orang & $40,8 \%$ \\
\hline 2 & Puas & 45 orang & $59,2 \%$ \\
\hline & Jumlah & $\mathbf{7 6}$ orang & $\mathbf{1 0 0} \%$ \\
\hline
\end{tabular}

Hasil statistik diketahui bahwa waktu rata-rata penyediaan dokumen rekam medis pada pasien dengan kategori puas lebih cepat dari pada waktu rata-rata penyediaan dokumen rekam medis pada pasien dengan kategori tidak puas. Hasil uji t-test independen diperoleh 
nilai $p(0,0001)<0,05$ artinya secara statistik menunjukkan ada perbedaan waktu rata-rata penyediaan dokumen rekam medis pada pasien dengan kategori tidak puas dan puas di Rumah Sakit Umum Permata Bunda Medan.

Tabel 3. Hubungan waktu penyediaan dokumen rekam medis dengan kepuasan pasien

\begin{tabular}{ccccc}
\hline Variabel & Nilai Rata-Rata & SD & Beda Rata-Rata & Nilai $\boldsymbol{p}$ \\
\hline Tidak Puas & 12,64 & 2,24 & 0,84 & \multirow{2}{*}{0,0001} \\
\hline Puas & 10,24 & 2,20 & & \\
\hline
\end{tabular}

\subsection{Pembahasan}

Lama waktu petugas menyediakan dokumen rekam medis rawat jalan di Rumah Sakit Permata Bunda Medan membutuhkan waktu rata-rata 11,3 menit. Perhitungan penyediaan rekam medis pada pasien rawat jalan di Rumah Sakit Permata Bunda Medan dimulai pada saat petugas pendaftaran selesai meregistrasi data pasien sampai tersedianya dokumen rekam medis.

Berdasatkan Standar Pelayanan Minimal di rumah sakit, lama waktu petugas menyediakan dokumen rekam medis yaitu kurang dari 10 menit untuk pelayanan pasien rawat jalan (Kemenkes RI, 2008). Hasil penelitian diperoleh 44 dokumen rekam medis $(57,89 \%)$ lama waktu penyediaannya lebih dari 10 menit. Penyediaan dokumen rekam medis di rumah Sakit Umum Permata Bunda Medan dilaksanakan petugas tanpa ada Standar Prosedur Operasional (SPO) yang jelas. SOP sangat penting agar petugas memiliki pedoman yang benar pencarian dan pengambialan dokumen rekam medis. Selain itu dikarenakan kurangnya rak penyimpanan sehingga berkas rekam medis tidak berada di tempatnya sehingga petugas rekam medis sulit untuk menemukan berkas rekam medis karena berkas rekam medis yang tidak beraturan letaknya.

Hasil penelitian menunjukan bahwa pasien dalam kategori puas lebih banyak $(59,2 \%)$ dari pada pasien dalam kategori tidak puas yaitu (40,8\%). Namun hasil uji statsistik diperoleh bahwa ada hubungan waktu penyediaan dokumen rekam medis dengan kepuasan pasien pada bagian pendaftaran di Rumah Sakit Umum Permata Bunda Medan $(p=0,0001)$. Terdapat perbedaan waktu rata-rata penyediaan dokumen rekam medis pada pasien dengan kategori tidak puas dan puas di Rumah Sakit Umum Permata Bunda Medan, artinya semakin cepat waktu penyediaan dokumen rekam medis maka pasien menjadi lebih puas, atau semakin lambat waktu penyediaan dokumen rekam medis maka pasien menjadi lebih tidak puas.

Pasien akan merasa puas apabila kinerja pelayanan kesehatan yang diperolehnya sama atau melebihi harapannya (Pohan, 2007). Menurut Azwar (1996) bahwa dimensi kepuasan adalah kepuasan yang mengacu kepada penerapan standard dan kode etik profesi, dalam hal ini adalah profesi rekam medis. Salah satu Standar Profesi Perekam Medis dan Informasi Kesehatan adalah mampu memanajemen rekam medis dan informasi kesehatan dan menjaga mutu rekam medis (Kepmenkes RI, 2007). Dengan menerapkan tata kelola manajemen rekam medis yang baik dan benar maka terjadi kesesuaian standard dan kode etik profesi pelayanan kesehatan dikatakan bermutu dan dapat memuaskan pasien. Penelitian Laeliyah \& Heru (2017) menunjukkan bahwa ada hubungan waktu tunggu pasien dengan kepuasan pasien rawat jalan RSUD Kabupaten Indramayu.

\section{KESIMPULAN}

Dari hasil penelitian yang dilakuan oleh peneliti didapatkan kesimpulan sebagai berikut:

1. Rata-rata penyediaan berkas rekam medis adalah 11,3 menit.

2. Pasien dalam kategori puas yaitu 45 orang $(59,2 \%)$ dan tidak puas yaitu 31 orang $(40,8 \%)$. 
3. Ada hubungan waktu penyediaan dokumen rekam medis dengan kepuasan pasien pada bagian pendaftaran di Rumah Sakit Umum Permata Bunda Medan $(p=0,0001)$.

\section{REFERENCES}

Asmuji. 2012. Manajemen Keperawatan: Konsep dan Aplikasi. Jogjakarta: Ar-. Ruzz Media.

Azwar, Azrul, 1996. Menjaga Mutu Pelayanan Kesehatan. Jakarta: Pustaka Sinar Harapan.

Bustami, 2011, Penjaminan Mutu Pelayanan Kesehatan \& Aksebtabilitasnya. Jakarta : Erlangga.

Erlindai, \& Apriana, D. (2019). Tinjauan kepuasan pasien pada pelayanan pendataran rawat jalan di UPT Rumah Sakit Khusus mata Medan tahun 2019. Jurnal Ilmiah Perekam Dan Informasi Kesehatan Imelda, 4(1), 573-580. http://jurnal.uimedan.ac.id/index.php/JIPIKI/article/view/79/81

Hardiansyah .2011. Kualitas Pelayanan Publik. Yogyakarta: Gava Media.

Kepmenkes RI Nomor 377 Tahun 2007 tentang Standar Profesi Perekam Medis dan Informasi Kesehatan.

Laeliyah, Nur \& Heru Subekti, 2017. Waktu Tunggu Pelayanan Rawat Jalan dengan Kepuasan Pasien Terhadap Pelayanan di Rawat Jalan RSUD Kabupaten Indramayu. Jkesvo (Jurnal Kesehatan Vokasional).Vol. 1 No 2 - April 2017. Diakses 28 Januari 2020. Tersedia: http://journal.ugm.ac.id/ jkesvo.

Menteri Kesehatan Republik Indonesia. Keputusan Menteri Kesehatan Republik Indonesia No 129 / MENKES / SK / II / 2008 Tentang Standard Pelayanan Minimal Rumah Sakit. Jakarta: Departemen Kesehatan Republik Indonesia.

Notoatmodjo . 2012. Metode Penelitian Kesehatan. Jakarta : Rineka Cipta.

Pohan S, 2007. Jaminan Mutu Pelayanan Kesehatan. Jakarta: Buku Kedokteran EGC.

\section{BIOGRAPHIES OF AUTHORS}

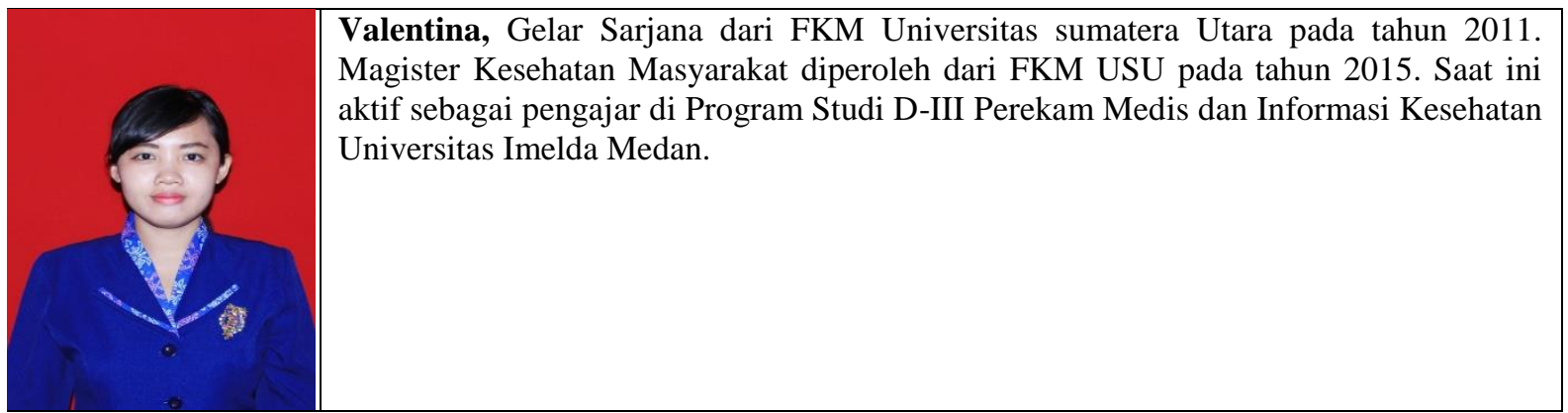

Jurnal Ilmiah Perekam dan Informasi Kesehatan Imelda, Vol. 5, No. 1, Februari 2020:40-44 